\title{
Comparison of the cultivation performance between Korean (Sugwawon No. 301) and Chinese strains (Huangguan No. 1) of kelp Saccharina japonica in an aquaculture farm in Korea
}

\author{
Eun Kyoung Hwang ${ }^{1}$, Fuli Liu ${ }^{2}$, Ki Hyun Lee ${ }^{1}$, Dong Su Ha ${ }^{1}$ and Chan Sun Park ${ }^{3, *}$ \\ ${ }^{1}$ Seaweed Research Center, National Institute of Fisheries Science, Haenam 59002, Korea \\ ${ }^{2} Y e l l o w$ Sea Fisheries Research Institute, Chinese Academy of Fishery Sciences, Qingdao 266071, China \\ ${ }^{3}$ Department of Marine and Fisheries Resources, Mokpo National University, Muan 58554, Korea
}

Saccharina japonica was introduced to both Korea and China from Hokkaido, Japan, and it has become an economically important species in both nations. After a long period of cultivation, several varieties of S. japonica have been developed in Korea and China. In this study, we conducted aquacultural research on the persistence of thalli from two kelp cultivars, one from China (Huangguan No. 1) and one from Korea (Sugwawon No. 301), between December 2015 and November 2016 in Haenam, Korea. The maximum length was $247.8 \pm 13.0$ and $227.5 \pm 42.0 \mathrm{~cm}$, respectively, which were significantly longer in Sugwawon No. 301 than in Huangguan No. 1. The maximum width was $29.9 \pm 5.4$ and $23.2 \pm 1.9$ $\mathrm{cm}$, respectively, which were significantly wider in Huangguan No. 1 than in Sugwawon No. 301. The mean biomass obtained from the culture ropes was for Sugwawon No. 301 was $3.5 \pm 0.3 \mathrm{~kg}_{\text {wet }} \mathrm{wt} \mathrm{m}^{-1}$ and for while Huangguan No. 1 was $3.1 \pm 1.0 \mathrm{~kg}$ wet wt $\mathrm{m}^{-1}$ of culture rope. After August, the persistence of the thalli of Sugwawon No. 301 was two months longer than that of Huangguan No. 1. We found that the Sugwawon No. 301 performed as well as the Huangguan No. 1 in Korean waters possibly due to increased flexibility as a result of the different cell arrangements of the two cultivars. Overall, the use of the Sugwawon No. 301 cultivar rather than the Huangguan No. 1 cultivar of S. japonica appears the best alternative to help to ensure a stable year round algal feed supply for the Korean abalone industry.

Key Words: biomass; cultivation; growth; Saccharina japonica; strain development

\section{INTRODUCTION}

Saccharina japonica (Areschoug) C. E. Lane, C. Mayes, Druehl \& G. W. Saunders is one of the most economically and ecologically important seaweeds in Korea, China, and Japan (Kim et al. 2005, 2017, Park and Hwang 2012, Liu et al. 2014). S. japonica is used as a food for humans as well as in aquaculture species, fertilizer, and raw material for alginic acid, mannitol and iodine extraction (Liu et al. 2012, Park et al. 2016). The history of S. japonica cultiva- tion of both Korea and China began with the introducing mature thalli from Japan. S. japonica was first introduced to Dalian, Liaoning Province, China in 1927 from Japan (Wu 1998). In Korea, S. japonica farming was first attempted in Ulsan in 1968, cultivation methods were developed in 1969 with the introduction of the mature thalli from Hokkaido, Japan (Jang and Gwon 1970) and commercial cultivation began in the Jumunjin $\left(37^{\circ} \mathrm{N}\right)$
(9) $\$$ This is an Open Access article distributed under the terms of the Creative Commons Attribution Non-Commercial License (http://creativecommons.org/licenses/by-nc/3.0/) which permits unrestricted non-commercial use, distribution, and reproduction in any medium, provided the original work is properly cited.
Received September 10, 2017, Accepted February 4, 2018

* Corresponding Author

E-mail: cspark85@mokpo.ac.kr

Tel: +82-61-450-2396, Fax: +82-61-452-8875 
region on the central eastern coast in 1971 (Sohn 1998). At this time there were no natural populations of $S$. japonica on the Korean peninsula south Wonsan Bay (below $39^{\circ} \mathrm{N}$ ) (Kang 1966). Since then, the commercial S. japonica cultivation has been expanded, and now the alga is cultivated all along the Korean coast $\left(34-37^{\circ} \mathrm{N}\right)$ except for Jeju Island.

Kelp aquaculture in China and Korea were both initiated by the transfer of S. japonica sporelings from Japan (Jang and Gwon 1970, Wu 1998). Subsequent generations of these sporlings have been exposed to different environmental conditions in each country. In recent years, specific cultivars of these farmed plants have been subject to different selective breeding program in order to develop varieties that are more productive and can be successfully cultured over a longer period each year.

The production of the S. japonica continues to increase in Korea with 442,637 tons wet weight was harvested in 2015 (Ministry of Oceans and Fisheries 2016). Recently, an abalone industry has been successfully development in Korea that is now worth over US $\$ 2$ billion annually (Son et al. 2014). The Korean abalone industry is supported by a stable production of farmed seaweed that forms the staple diet of the farmed abalone. The increasing demand for seaweed by abalone farmers has led to a substantial increase in the area being used for $S$. japonica farming in Korea: between 2001 and 2015 the area used for S. japonica culture increased by $671 \%$ to 9,147 ha (Korean Statistical Information Service 2017). The rapid increase of the seaweed industry has been supported by technological developments such as artificial seedlingrearing and by development of an autumn sporelingrearing method (Sohn 1998). Following successful selective breeding research, the Sugwawon No. 301 cultivar has been developed via selective breeding for an extended cultivation period (Hwang et al. 2017). The cultivar is being prepared for registration as a Korean government's new variety and will be distributed to fishermen after registration.

In China, studies on hybridization, inbreeding and selection have led to stable and improved strains of $S$. japonica with higher production rates and iodine content. Large-scale production experiments showed that these new strains yielded up to $40 \%$ more biomass and their iodine content was $20-58 \%$ higher than the control plants (Zhang et al. 2007, Liu et al. 2014, Zhao et al. 2016). These new strains were introduced to Saccharina farms and are now grown in large quantities in North China (Wu 1998, Liu et al. 2014). Huangguan No. 1 is a new variety, rep- resentative high temperature tolerance strain, has been developed by repeated selfing / inbreeding and targeted selection (Liu et al. 2014). The purpose of this study was to conduct a growth comparison between the two high temperature resistant varieties, Huangguan No. 1 of China and the Sugwawon No. 301 of Korea by cultivating them for the first time in the same seaweed farm in Korea.

\section{MATERIALS AND METHODS}

\section{Algal sampling}

The breeding program of the Huangguan No. 1 started from 2005, and researchers in Yellow Sea Fisheries Research Institute, China successful bred the $\mathrm{F}_{1}$ generation in 2006. They named this new cultivar as Huangguan No. 1 and applied for a certificate for the new variety from the Chinese government in 2011. We collected the matured $\mathrm{F}_{10}$ sporophytes (2.2 $\pm 0.5 \mathrm{~m}$ in mean length, $\mathrm{n}=3$ ) of this cultivar in May 2015 at the same culture farm in Fujian Province, China $\left(26^{\circ} 19^{\prime} 30^{\prime \prime} \mathrm{N}, 119^{\circ} 49^{\prime} 56^{\prime \prime} \mathrm{E}\right)$.

The breeding procedure for the cultivation period extension of S. japonica in Korea was conducted from 2009 by Hwang et al. (2017) in Haenam, Korea $\left(34^{\circ} 38^{\prime} 06^{\prime \prime} \mathrm{N}\right.$, $126^{\circ} 15^{\prime} 57^{\prime \prime}$ E). We named the $\mathrm{F}_{3}$ generation Sugwawon No. 301, and collected the matured thalli $(1.6 \pm 0.4 \mathrm{~m}$ in mean length, $\mathrm{n}=3$ ) in September 2015 at the same culture farm in Haenam, Korea.

\section{Zoospore seeding}

At the laboratory, the plants were rinsed in sterile, filtered seawater and the sorus excised without any vegetative portions of plant. These were then dried in dark and humid conditions for $1 \mathrm{~h}$. The sorus subsequently released zoospores when it was reimmersed in seawater. Sterilized seed fiber segments (polyvinylchloride fiber, 4 $\mathrm{cm}$ in length, $1.43 \pm 0.12 \mathrm{~mm}$ in diameter) were used for zoospore seeding instead of seed frame normally used for kelp cultivation in Korea (Hwang et al. 2014). Seedlings of Sugwawon No. 301 and Huangguan No. 1 developed from these zoospores were reared in $0.5 \mathrm{~L}$ culture flasks under $10: 14 \mathrm{~h} \mathrm{~L}: \mathrm{D}, 15^{\circ} \mathrm{C}$ and $20 \mu \mathrm{mol} \mathrm{m}^{-2} \mathrm{~s}^{-1}$ until December 2015. The seedlings were grown up to $255 \mu \mathrm{m}$ and $280 \mu \mathrm{m}$ in length of micro-sporophytes, respectively in Sugwawon No. 301 and Huangguan No. 1. 


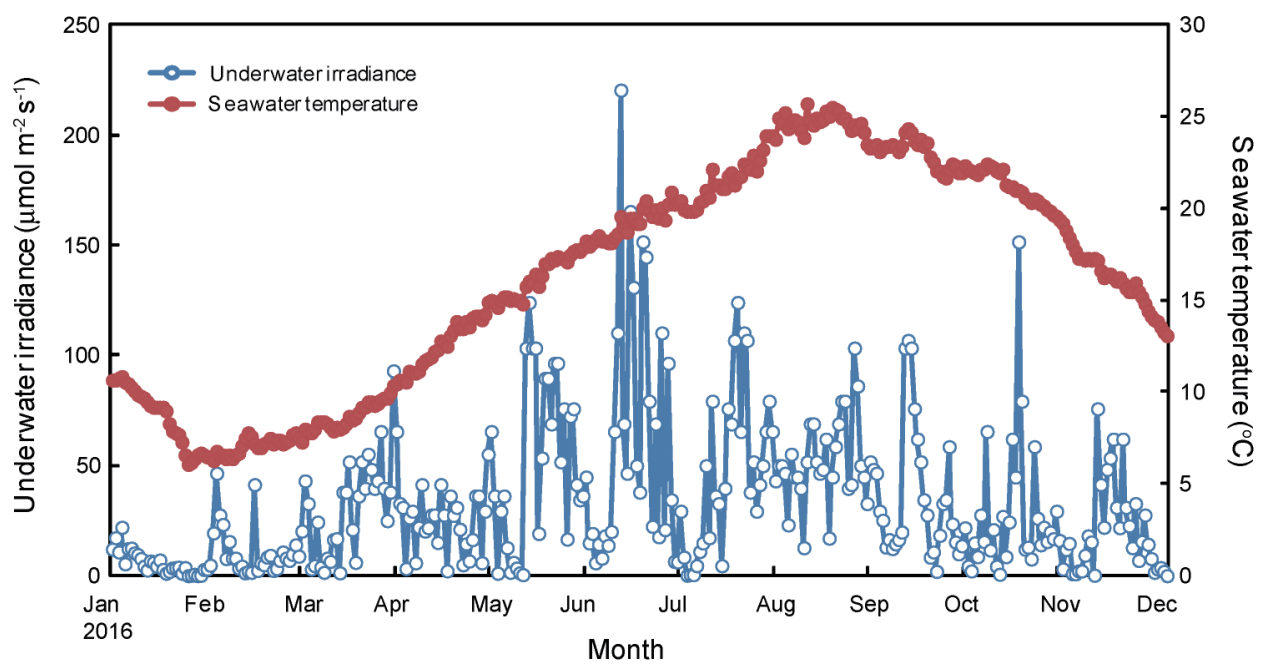

Fig. 1. Seawater temperature and underwater irradiance at the experimental site in Haenam, Korea, between January and December 2016. Temperature was monitored by UTBI-001 and Hobo UA 002-64 sensor (USA) placed on the transplantation rope of Saccharina japonica in the experimental site of $1 \mathrm{~m}$ depth. The temperature sensor was downloaded every month.

\section{On-growing}

Seed fibers with the attached young sporophytes of Sugwawon No. 301 or Huangguan No. 1 were inserted into culture ropes (polypropyrene, $12 \mathrm{~mm}$ in diameter) at $20 \mathrm{~cm}$ intervals. Two experimental ropes (100 $\mathrm{m}$ in length) were set up for the two cultivars. Those ropes were then transferred to the Haenam culture farm for on-growing. All ropes were arranged parallel to the direction of current flow. Young thalli were on-grown from December 2015 to November 2016. Growth was assessed every month by measuring the maximum length, width, thickness of thalli as well as weight, biomass and density per 1 meter of culture rope. Maturity was analyzed by measuring the proportion of sorus formation area on a monthly basis. At least 30 plants were randomly sampled every month for growth and maturity measurement of each cultivars. Also samples for biomass and density measurement were sampled by triplicate of whole plants in $1 \mathrm{~m}$ rope.

Environmental factors at the culture site, such as water temperature and salinity, were measured by a logging multi-parameter probe (YSI-85; YSI Co., Yellow Springs, $\mathrm{OH}, \mathrm{USA})$. Temperature and light intensity were monitored by UTBI-001 and Hobo UA 002-64 sensor (Onset Computer Corp., Bourne, MA, USA) on the S. japonica transplantation rope at the experimental site. Light intensity (lumens $\mathrm{ft}^{-2}$ ) was measured using a Hobo data logger and converted to photon flux density $\left(\mu \mathrm{mol} \mathrm{m}^{-2} \mathrm{~s}^{-1}\right)$ by concurrent quantum measurements using an LI-1400 data logger and an LI 193SA (LI-COR Inc., Lincoln, NE, USA). The temperature and irradiance sensor were changed every month.

\section{Statistical analyses}

A paired t-test and 95\% probability level was used to determine whether there was a statistically significant difference in the mean growth between cultivars for each cultivation stages. A percentage data for maturation was normalized by arcsine transformation (Parker 1979) before statistical analyses.

\section{RESULTS}

\section{Cultivation environment}

Water temperature at the on-growing site varied from 6.1 to $25.7^{\circ} \mathrm{C}$ during the experimental periods (Fig. 1). Maximum water temperatures were recorded in August 2016 with the minimum occurring in January 2016. Salinity ranged between 30.0 and $33.1 \mathrm{psu}$. Underwater irradiance was highly variable, ranging between 0.216 and $220.4 \mu \mathrm{mol} \mathrm{m}^{-2} \mathrm{~s}^{-1}$. The substratum depth was $15 \mathrm{~m}$ at the culture site and thalli were grown successfully on the culture rope at $1 \mathrm{~m}$ depth. 

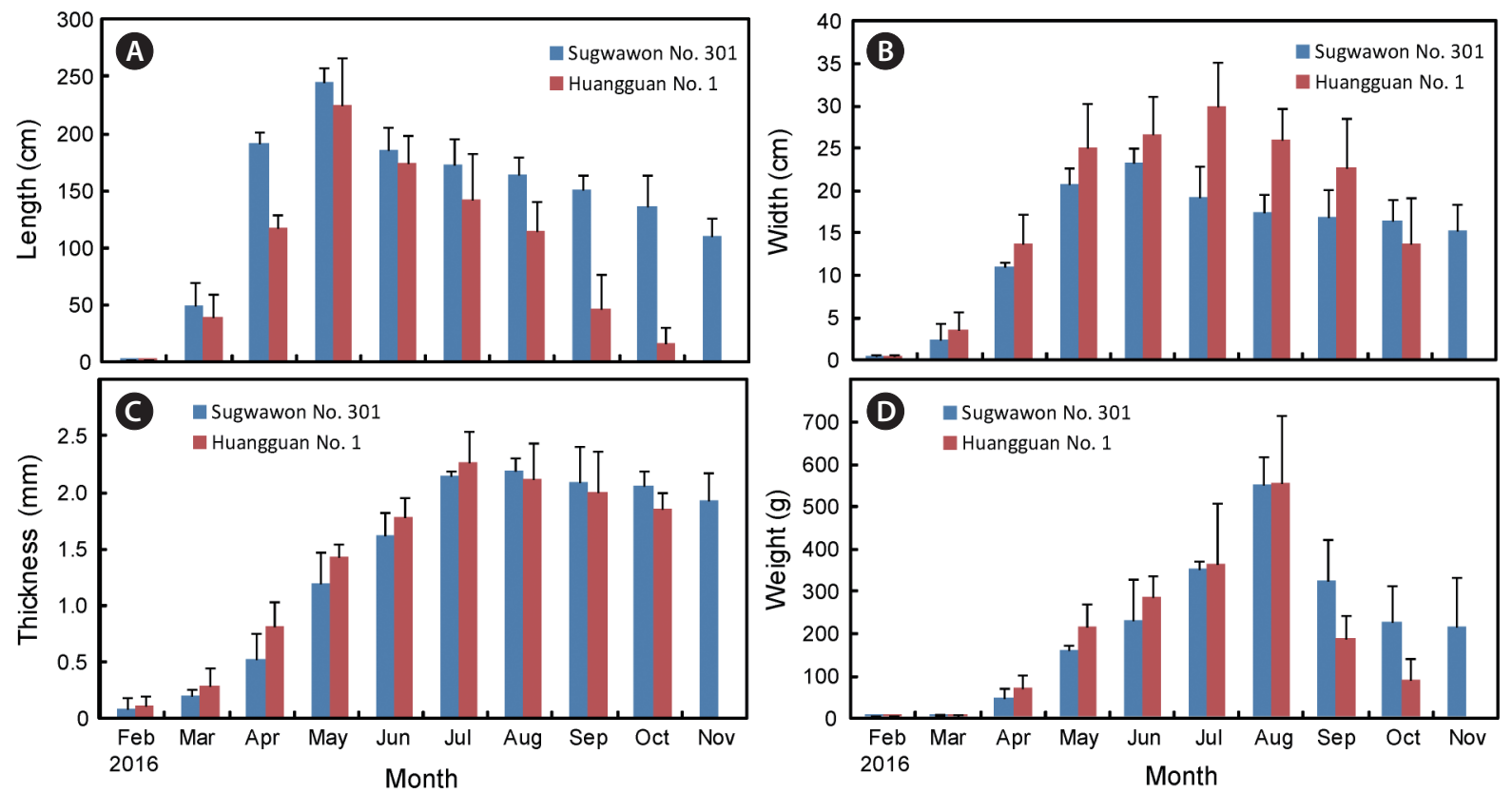

Fig. 2. Growth of a Korean (Sugwawon No. 301) and Chinese (Huangguan No. 1) varieties of Saccharina japonica at the same culture farm in Haenam, Korea between February and November 2016. (A) Length (cm). (B) Width (cm). (C) Thickness (mm). (D) Weight (g).

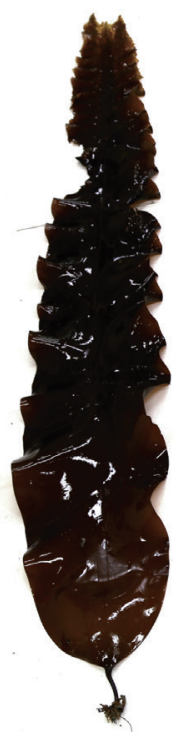

Huangguan No. 1

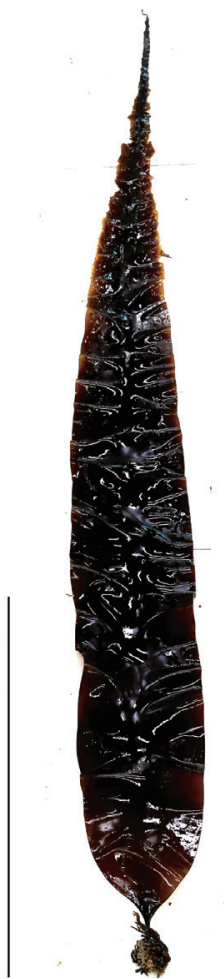

Sugwawon No. 301

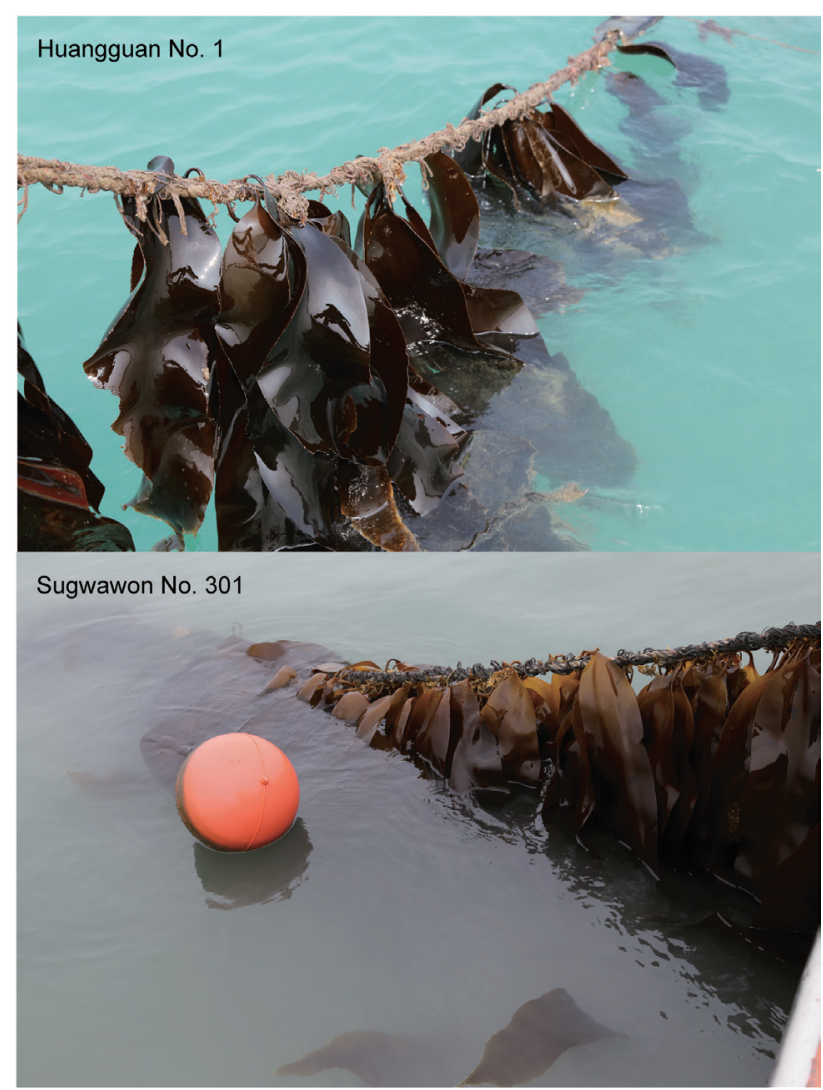

Fig. 3. Morphological comparison between Korean (Sugwawon No. 301) and Chinese (Huangguan No. 1) varieties of Saccharina japonica at their maximum weight in August 2016. Scale bar represents: $1 \mathrm{~m}$. 


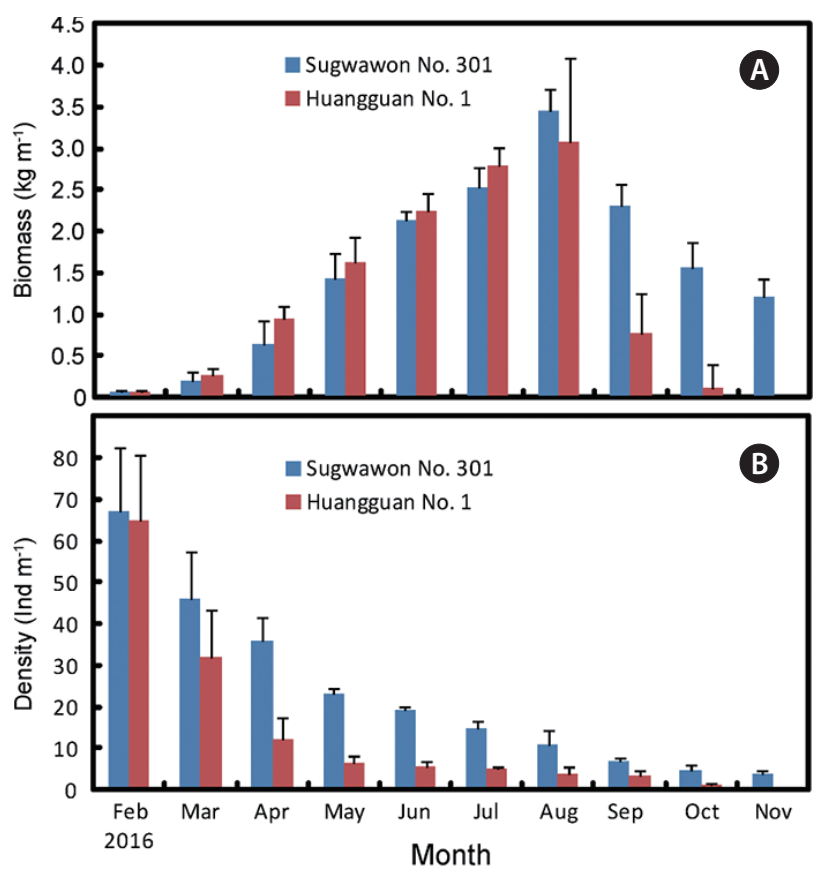

Fig. 4. Biomass (A) and density (B) of Korean (Sugwawon No. 301) and Chinese (Huangguan No. 1) varieties of Saccharina japonica at the same culture farm in Haenam, Korea between February and November 2016.

\section{Growth}

Length was significantly greater in Sugwawon No. 301 than in Huangguan No. 1 over all cultivation periods $(\mathrm{p}<$ 0.05) (Fig. 2A). Between January and May 2016, Sugwawon No. 301 increased in mean length from 0.1 to $247.8 \pm 13.0$ $\mathrm{cm}$ (growth rate $1.652 \pm 0.087 \mathrm{~cm} \mathrm{~d}^{-1}$ ), and Huangguan No. 1 increased from 0.1 to $227.5 \pm 42.0 \mathrm{~cm}$ (growth rate $1.517 \pm 0.280 \mathrm{~cm} \mathrm{~d}^{-1}$ ). Maximum mean length increase occurred in May 2016 for both varieties (Fig. 2A). Width was significantly larger in Huangguan No. 1 than in Sugwawon No. $301(p<0.01)$. Mean width of Sugwawon No. 301 increased from 0.05 to $23.2 \pm 1.9 \mathrm{~cm}$, and Huangguan No. 1 increased from 0.05 to $29.9 \pm 5.4 \mathrm{~cm}$ over the cultivation period (Fig. 2B). Mean thickness of Sugwawon No. 301 increased from 0.01 to $2.20 \pm 0.12 \mathrm{~mm}$, and Huangguan No. 1 increased from 0.01 to $2.27 \pm 0.29 \mathrm{~mm}$ over the cultivation period, but thickness were not significantly different ( $p>0.05$ ) (Fig. 2C). Mean weight of Sugwawon No. 301 increased from 0.01 to $550.1 \pm 67.7 \mathrm{~g}$, and Huangguan No. 1 increased from 0.01 to $555.8 \pm 159.2 \mathrm{~g}$ over the cultivation period (Fig. 2D). Weight was not significantly different between the two cultivars ( $p>0.05$ ). Morphologically the Sugwawon No. 301 variety was longer and narrower than the Huangguan No. 1 variety (Fig. 3).

\section{Biomass and density}

Biomass of Sugwawon No. 301 and Huangguan No. 1 increased from April and was greatest in August 2016 in this experiment (Fig. 4A). After showing the maximum biomass in August 2016, Huangguan No. 1 began to decline significantly $(\mathrm{p}<0.05)$, and disappear completely after October. But the Sugwawon No. 301 variety continued to be present on the ropes through to November. The mean density of Sugwawon No. 301 plants decreased from 67 to $4.0 \pm 0.7$ ind. $\mathrm{m}^{-1}$, and Huangguan No. 1 plants decreased from 65 to 0 ind. $\mathrm{m}^{-1}$ over the cultivation period (Fig. 4B). From March, the mean density of Huangguan No. 1 began to decrease significantly $(\mathrm{p}<0.05)$ compared to Sugwawon No. 301.

\section{Maturation}

The formation of reproductive sori was observed from May to November for the Sugwawon No. 301 variety and from July to September for the Huangguan No. 1 variety. However, proportion of reproductive plants of Huangguan No. 1 was significantly retarded $(\mathrm{p}<0.05)$ compared to Sugwawon No. 301 (Table 1). The maximum proportion of the reproductive thallus was $92.5 \%$ at November for the Sugwawon No. 301 variety and the maximum proportion of the reproductive thallus was $48.5 \%$ at September for the Huangguan No. 1 variety (Table 1).

\section{DISCUSSION}

The kelp transplanted to different regions grew in accordance with the transplanted environment and, in particular, cultivated cultivars developed as a result of breeding for aquaculture. The Huangguan No. 1 and Sug-

Table 1. Proportion of reproductive thallus of the two Saccharina japonica varieties, Sugwawon No. 301 and Huangguan No. 1

\begin{tabular}{lcc}
\hline \multirow{2}{*}{ Month } & \multicolumn{2}{c}{ Proportion of reproductive thallus (\%) ${ }^{\mathrm{a}}$} \\
\cline { 2 - 3 } & Sugwawon No.301 & Huangguan No. 1 \\
\hline December-April & Sterile & Sterile \\
May & 5.2 & Sterile \\
June & 6.5 & Sterile \\
July & 15.4 & 16.2 \\
August & 54.2 & 25.6 \\
September & 85.4 & 48.5 \\
October & 89.2 & Detached \\
November & 92.5 & Detached \\
\hline
\end{tabular}

${ }^{a}$ Values represent mean of triplicate groups $(n=90)$. 


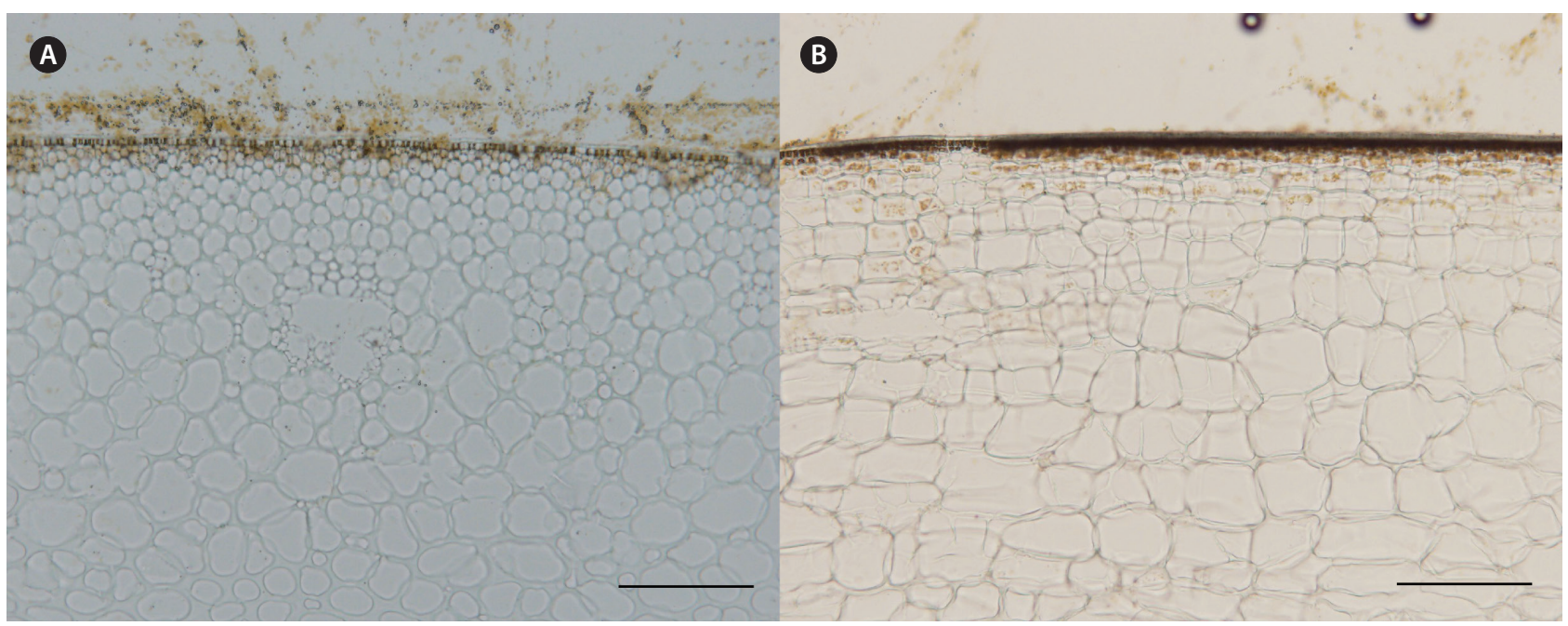

Fig. 5. Cross-sectioned of thali from Sugwawon No. 301 (A) and Huangguan No. 1 (B) varieties of Saccharina japonica. Samples collected from the same culture farm in Haenam, Korea at June 2016. Scale bars represent: A \& B, $200 \mu \mathrm{m}$.

wawon No. 301 are kelp varieties developed by selective breeding in China and Korea, respectively. In this study, the two varieties grown in the same environment showed very different performances. Korean kelp farmers predicted that the Huangguan No. 1 variety would be able to adapt to higher water temperatures (in $26^{\circ} 19^{\prime} 30^{\prime \prime} \mathrm{N}$ ) than the Sugwawon No. 301 variety and would be able to cultivate for a longer period of cultivation. In order to provide a stable food supply of abalone farming in Korea, preference is given to kelp varieties that maintain biomass after August, which is the end of general kelp farming season in Korea (Hwang et al. 2009).

Liu et al. (2014) reported that Huangguan No. 1 was highly productive in Fujian to Liaoning Province, with a mean blade length of $396 \mathrm{~cm}$. However, in this trial the mean length of Huangguan No. 1 reached only 227 cm (Fig. 2). And it was smaller than the Sugwawon No. 301 variety grown within the trial. However, the width of Huangguan No. 1 was wider than Sugwawon No. 301 through cultivation period.

The period of maximum biomass production for $S$. japonica suggests that there is a strong negative correlation with seawater temperature. This is one of the key factors affecting the growth of kelp (Lüning 1980, Dring 1982, Gerard and Du Bois 1988, tom Dieck 1992). In Korea, the seawater temperature generally exceeds the optimum temperature range for growth of $S$. japonica from June until October. During this time the activity of the thalli decreases and biomass decreases sharply as the plants mature. However, the Sugwawon No. 301 varieties se- lected here, appeared to have an increased ability to endure at higher temperatures and were found to maintain a significant amount of biomass until November (Fig. 4). The change from the vegetative to the reproductive condition in simple algae involves virtually no further growth (Lobban et al. 1985). The Huangguan No. 1 exhibited delayed maturation compared to the Sugwawon No. 301 (Table 1). The delay in maturation and associated decay of the frond, at least in part explains the retention of kelp biomass in this variety over a longer timeframe. Nonetheless, the biomass of Huangguan No. 1 was less than the biomass of Sugwawon No. 301 after maturity.

Biomass and density of Huangguan No. 1 decreased rapidly after September (Table 1). This is usually the season of typoons and rough waves in this area. Two typoons affected the experimental area in September 2016 (National Typoon Center, Korea). It is appears that the Huangguan No. 1 variety was easily broken by wave action due to wide and thick thalli minimizing flexibility. Analysis of cross sections of Sugwawon No. 301 and Huangguan No. 1 thalli showed that Sugwawon No. 301 had an irregular arrangement of spherical large and small cells whilst the Huangguan No. 1 variety had large rectangular cells layered and arranged in a more regular pattern (Fig. 5). It is unclear why these cell arrays differ, but it is perhaps due to adaptation to differences in environmental conditions but it is possible that these cell arrangements influence the tolerance of each strain to turbulent water motion. Seaweed morphology is adapted for environmental conditions such as nutrient acquisition and 
tolerance of water movement (Lobban et al. 1985, Robinson et al. 2013).

In this study, the Sugwawon No. 301 variety could be cultured for a longer period and produced a greater biomass than the Huangguan No. 1. It is probable that this was a result of selecting strains that had both increased tolerance to higher seawater temperature, later maturation and resistance to wave action (Hwang et al. 2017). Further research will needed to analyze genetic and biochemical differences between normal cultivar and Sugwawon No. 301 that allowed the elongation of the culture period.

\section{ACKNOWLEDGEMENTS}

Genetic resources exchange of seaweed between Korea and China followed by 2014-2016 Agenda of the Annual Presidential Meeting of Fisheries Research Institutes among Korea, China, and Japan. This work was supported by a grant from the National Institute of Fisheries Science (R2018011), and a grant from the Priority Research Centers Program through the National Research Foundation of Korea (NRF) by the Ministry of Education, Science and Technology (2009-0093828).

\section{REFERENCES}

Dring, M. J. 1982. The biology of marine plants. Edward Arnold Publishers, London, 199 pp.

Gerard, V. A. \& Du Bois, K. R. 1988. Temperature ecotypes near the southern boundary of the kelp Laminaria saccharina. Mar. Biol. 97:575-580.

Hwang, E. K., Baek, J. M. \& Park, C. S. 2009. The mass cultivation of Ecklonia stolonifera Okamura as a summer feed for the abalone industry in Korea. J. Appl. Phycol. 21:585-590.

Hwang, E. K., Ha, D. S. \& Park, C. S. 2017. Strain selection and initiation timing influence the cultivation period of Saccharina japonica and their impact on the abalone feed industry in Korea. J. Appl. Phycol. 29:2297-2305.

Hwang, E. K., Hwang, I. K., Park, E. J., Gong, Y. G. \& Park, C. S. 2014. Development and cultivation of $\mathrm{F}_{2}$ hybrid between Undariopsis peterseniana and Undaria pinnatifida for abalone feed and commercial mariculture in Korea. J. Appl. Phycol. 26:747-752.

Jang, J. W. \& Gwon, S. H. 1970. Studies on Laminaria cultivation. Report of the National Fisheries Research and Development Agency. Vol. 5. National Institute of Fisheries
Science, Busan, pp. 63-74.

Kang, J. W. 1966. On the geographical distribution of marine algae in Korea. Bull. Pusan Fish. Coll. 7:1-125.

Kim, H. G., Park, J. G. \& Kim, D. S. 2005. Comparative laboratory culture studies of the native kelp, Kjellmaniella crassifolia and the introduced kelp Laminaria japonica in east coast of Korea. J. Aquac. 18:299-304.

Kim, J. K., Yarish, C., Hwang, E. K., Park, M. \& Kim, Y. 2017. Seaweed aquaculture: cultivation technologies, challenges and its ecosystem services. Algae 32:1-13.

Korean Statistical Information Service. 2017. Korean statistical information service. Available from: http://kosis.kr. Accessed Jan 5, 2017.

Liu, F., Sun, X., Wang, F., Wang, W., Liang, Z., Lin, Z. \& Dong, Z. 2014. Breeding, economic traits evaluation, and commercial cultivation of a new Saccharina variety "Huangguan No.1". Aquac. Int. 22:1665-1675.

Liu, F., Yao, J., Wang, X., Repnikova, A., Galanin, D. A. \& Duan, D. 2012. Genetic diversity and structure within and between wild and cultivated Saccharina japonica (Laminariales, Phaeophyta) revealed by SSR markers. Aquaculture 358-359:139-145.

Lobban, C. S., Harrison, P. J. \& Duncan, M. J. 1985. The physiological ecology of seaweeds. Cambridge University Press, New York, 242 pp.

Lüning, K. 1980. Critical levels of light and temperature regulating the gametogenesis of three Laminaria species (Phaeophyceae). J. Phycol. 16:1-15.

Ministry of Oceans and Fisheries. 2016. Statistical data of the Ministry of Oceans and Fisheries. Available from: http:// www.fips.go.kr. Accessed Jan 5, 2017.

Park, C. S. \& Hwang, E. K. 2012. Seasonality of epiphytic development of the hydroid Obelia geniculata on cultivated Saccharina japonica (Laminariaceae, Phaeophyta) in Korea. J. Appl. Phycol. 24:433-439.

Park, H. -J., Lee, M. -S., Shim, H. S., Lee, G. -R., Chung, S. Y., Kang, Y. M., Lee, B. -J., Seo, Y. B., Kim, K. S. \& Shim, I. 2016. Fermented Saccharina japonica (Phaeophyta) improves neuritogenic activity and TMT-induced cognitive deficits in rats. Algae 31:73-84.

Parker, R. E. 1979. Introductory statistics for biology. 2nd ed. Edward Arnold, London, 122 pp.

Robinson, N., Winberg, P. \& Kirkendale, L. 2013. Genetic improvement of macroalgae: status to date and needs for the future. J. Appl. Phycol. 25:703-716.

Sohn, C. H. 1998. The seaweed resources of Korea. In Critchley, A. T. \& Ohno, M. (Eds.) Seaweed Resources of the World. Japan International Cooperation Agency, Yokosuka, pp. 15-33.

Son, M. -H., Park, M. -W., Kim, B. -H. \& Lee, S. -W. 2014. A 
study on the comparative analysis of business performance of abalone seed, Haliotis discus hannai by region and farming size in the land-based system. J. Fish. Bus. Admin. 46:1-13.

tom Dieck, I. 1992. North Pacific and North Atlantic digitate Laminaria species (Phaeophyta): hybridization experiments and temperature responses. Phycologia 31:147163.

Wu, C. Y. 1998. The seaweed resources of China. In Critchley, A. T. \& Ohno, M. (Eds.) Seaweed Resources of the World. Japan International Cooperation Agency, Yokosuka, pp.
34-46.

Zhang, Q. -S., Tang, X. -X., Cong, Y. -Z., Qu, S. -C., Luo, S. -J. \& Yang, G. -P. 2007. Breeding of an elite Laminaria variety 90-1 through inter-specific gametophyte crossing. J. Appl. Phycol. 19:303-311.

Zhao, X. B., Pang, S. J., Liu, F., Shan, T. F., Li, J., Gao, S. Q. \& Kim, H. G. 2016. Intraspecific crossing of Saccharina japonica using distantly related unialgal gametophytes benefits kelp farming by improving blade quality and productivity at Shanggou Bay, China. J. Appl. Phycol. 28:449-455. 